\title{
Drug eluting balloon-side branch with/without cross-stenting technique - alternatives for conventional bifurcation stenting?
}

\section{Mario Sičaja*, Boris Starčević}

University Hospital Dubrava, Zagreb, Croatia
RECEIVED:

January 31, 2016

ACCEPTED:

February 20, 2016

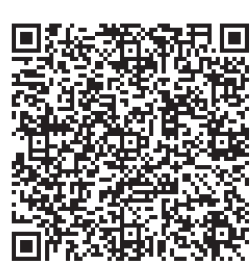

KEYWORDS: bifurcation technique, drug eluting balloon, stent

CITATION: Cardiol Croat. 2016;11(3-4):115. | DOI: http://dx.doi.org/10.15836/ccar2016.115

*ADDRESS FOR CORRESPONDENCE: Mario Sičaja, Klinička bolnica Dubrava, Avenija Gojka Šuška 6, HR-10000 Zagreb, Croatia. / Phone: +385-91-40-60-989 / E-mail: mario.sicaja@gmail.com

ORCID: Mario Sičaja, http://orcid.org/0000-0003-0773-4720 • Boris Starčević, http://orcid.org/0000-0002-3090-2772

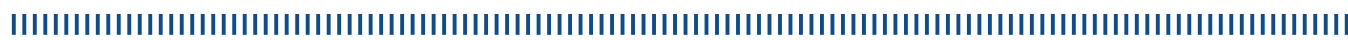

In the last few years several technical advancements were introduced in the treatment of coronary bifurcations lesions. Even though several bifurcation stenting techniques are available, majority of them are associated with the high incidence of target lesion revascularization failure, mainly due to the complications of the side-branch. Cross-stenting technique, which represents modified Culotte stent technique and provisional $\mathrm{T}$ stenting with the treatment of side branch with drug eluting balloon (DEB) in some aspects reduce several technical limitations which are common for one or two-stent technique..$^{1-3}$ Here we present short description of above mentioned techniques with two case examples from our clinical practice.

First patient is 48-years-old male hospitalized due to non ST-segment elevation acute myocardial infarction with preserved left ventricular ejection fraction accompanied with mild mitral regurgitation. Culprit lesion was true bifurcation (Medina 1,1,1) on circumflex artery (ACx) and first obtuse marginal branch (OM). Patient was treated successfully with the PCI OM (Medtronic Integrity stent 3,5x19mm) with provisional T stenting of ACx with DEB (SeQuent Please balloon catheter, $3 \mu \mathrm{g}$ paclitaxel $/ \mathrm{mm}^{2}$ balloon surface) with proximal optimization technique (POT).

Second patient is 70-years-old male, with long lasting hypertension and history of coronary artery disease, with previous PCI preformed in the region of left anterior descending artery (LAD) due to ST-segment elevation myocardial infarction. He was admitted because of instable angina pectoris, with echocardiography showing preserved ejection fraction with mild mitral regurgitation. Culprit lesion was true bifurcation (Medina 1,1,1), also present on ACX and OM. In this case, the treatment of choice was cross stenting technique with two stents resulting in PCI ACX/OM (DES Resolute Integrity 2,5x16mm and DES Resolute Integrity 2,5x24mm) finalized with POT.

In six-month follow-up both patients are doing fine, with angina only during strenuous or prolonged physical activity (Canadian Cardiovascular Society grading - CCS 1).

In conclusion, the utilization of above mentioned techniques in everyday clinical practice is easy, timesaving and with acceptable risk in short term follow-up.

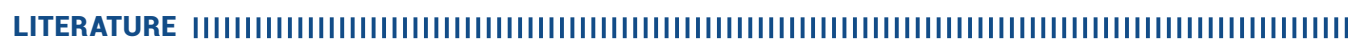

1. Kawasaki T, Koga H, Serikawa T. Modified culotte stenting technique for bifurcation lesions: the cross-stenting technique. J Invasive Cardiol. 2010;22(5):243-6. DOI: http://www.ncbi.nlm.nih.gov/pubmed/20440044

2. Lassen JF, Holm NR, Stankovic G, Lefèvre T, Chieffo A, Hildick-Smith D, et al. Percutaneous coronary intervention for coronary bifurcation disease: consensus from the first 10 years of the European Bifurcation Club meetings. EuroIntervention. 2014;10(5):545-60. DOI: http://dx.doi.org/10.4244/EIJV1015A97

3. Mathey DG, Wendig I, Boxberger M, Bonaventura K, Kleber FX. Treatment of bifurcation lesions with a drug-eluting balloon: the PEPCAD V (Paclitaxel Eluting PTCA Balloon in Coronary Artery Disease) trial. EuroIntervention. 2011;7 Suppl K:K61-5. DOI: http://dx.doi.org/10.4244/EIJV7SKA11 